\title{
Risk in clinical trials
}

\author{
Peter E Lipsky
}

On July 24, 2007, a subject in a gene therapy trial of inflammatory arthritis died, 22 days after receiving an injection of a genetically engineered adeno-associated virus encoding a tumor necrosis factor receptor construct. The subject was a participant in an openlabel phase I/II trial sponsored by a biotech company, Targeted Genetics, designed to examine the safety and efficacy of this intervention in individuals with a partial response to standard antirheumatic therapy. This case has stimulated great interest in the lay press, perhaps because of the public discussions of gene therapy approaches and also because the patient was a 36-year-old mother of a 5year-old daughter (Weiss $\mathrm{R}$, Washington Post August 6, 2007). Investigations into the cause of death are being carried out by the FDA, the company, and others. An initial autopsy report indicated that the subject had disseminated histoplasmosis. She lived in an endemic area and was also being treated with adalimumab (Weiss R, Washington Post August 17, 2007).

Every death in a clinical trial of rheumatic disease is tragic and unexpected, because most trials do not include patients in extremis. When there is a serious adverse event or a death in such a trial, therefore, it is a cause for extraordinary concern and soul searching by all involved. Was something done incorrectly that contributed to the untoward event? Was the science wrong? Were confounding circumstances unappreciated? Was there insufficient knowledge of the agent or the disease? Was the patient adequately informed and protected from risk?

The investigations that are underway will address some of these matters, but will focus narrowly on this particular case and will not examine the conduct of clinical trials in general to determine whether there are sufficient safeguards for patient safety. Over the past decade, clinical trials in rheumatic disease have become a thriving business, generating considerable
When there

is a serious

adverse event

or a death in

such a trial,

therefore, it

is a cause for

extraordinary

concern and

soul searching

by all involved

PE Lipsky is the Editorin-Chief of Nature Clinical Practice Rheumatology.

\section{Competing interests \\ The author declared no} competing interests.

www.nature.com/clinicalpractice doi:10.1038/ncprheum0649 profits for pharmaceutical companies as well as prominence and financial rewards for clinical trialists. The success of this activity with regard to the treatment of patients with some rheumatic diseases has been stunning and has stimulated tremendous interest in testing new products by companies, and participation in trials by clinicians.

Although this activity invigorates rheumatology, it remains uncertain whether patient safety is adequately protected. Although an obvious concern to clinicians, this is also an area of intense public discussion. Sigrid Fry-Revere argued in the Los Angeles Times of August 15, 2007, that patients should not be precluded from entering trials that are inherently risky: "Overemphasizing safety prevents patients from taking a calculated risk when they think it is worthwhile". Although patients clearly have the right to choose to participate in clinical trials, there is a great deal of scholarly literature concerning "therapeutic misconception", or the tendency of patients to confuse recruitment into a trial with recommendations by a physician for individualized treatment (Chen DT et al. [2003], Ann Intern Med 138: 669-672). In addition, patients can view the study intervention as treatment rather than something whose efficacy is being investigated under the principle of equipoise (Heckerling PS et al. [2005] Ann Intern Med 142: 309).

Many aspects of this case require examination, including the cause of death, the safety of the intervention, the appropriateness of the trial design, the anticipated risk:benefit ratio, the wisdom of patient selection and recruitment, the process of commercial review board approval and the nature of patient consent. In a wider sense this case should stimulate the rheumatology community to consider the nature of clinical trials in our discipline, and initiate a broader discussion of what can be done to ensure that science progresses but with minimum risk to involved patients. 